\title{
Oxygen-Vacancy Engineering of Cerium-Oxide Nanoparticles for Antioxidant Activity
}

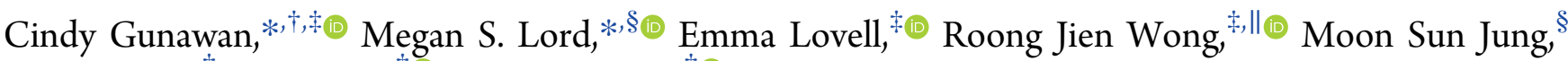 \\ Diana Oscar, ${ }^{\ddagger}$ Riti Mann, ${ }^{\dagger}$ and Rose Amal ${ }^{\ddagger}$ \\ †ithree institute, University of Technology Sydney, Sydney, New South Wales 2007, Australia \\ ${ }^{\ddagger}$ Particles and Catalysis Research Group, School of Chemical Engineering, and ${ }^{\S}$ Graduate School of Biomedical Engineering, The \\ University of New South Wales, Sydney, New South Wales 2052, Australia \\ "Applied Chemistry and Environmental Science, School of Science, RMIT University, Melbourne, Victoria 3000, Australia
}

\section{Supporting Information}
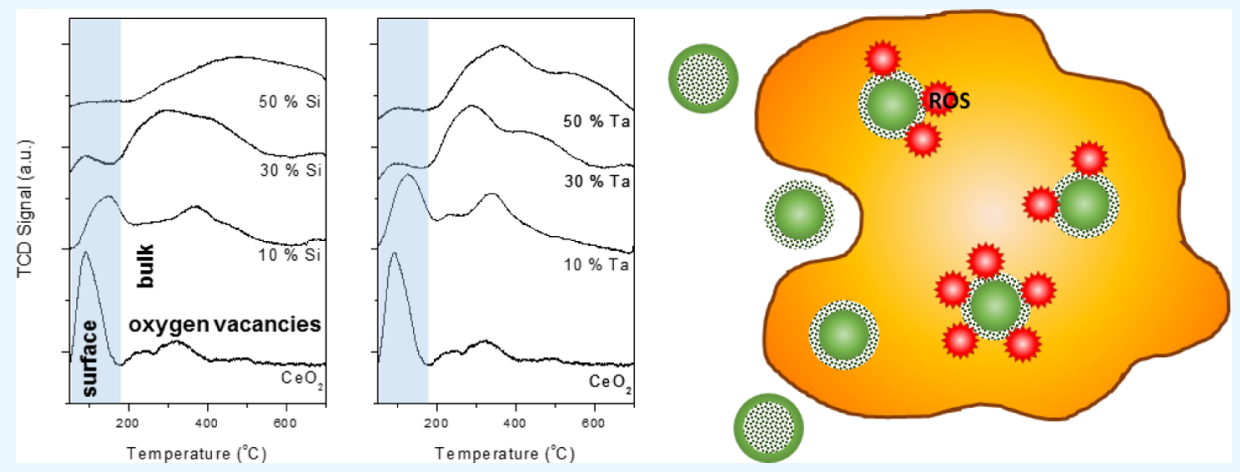

ABSTRACT: To address an important challenge in the engineering of antioxidant nanoparticles, the present work devised a surface-to-bulk migration of oxygen vacancies in the oxygen radical-scavenging cerium-oxide nanoparticles. The study highlights the significance of surface oxygen vacancies in the intended cellular internalization and, subsequently, the radical scavenging activity of the nanoparticles inside the cells. The findings advise future development of therapeutic antioxidant nanomaterials to also include engineering of the particles for enhanced surface defects not only for the accessibility of their oxygen vacancies but also, equally important, rendering them bioavailable for cellular uptake.

\section{INTRODUCTION}

Reactive oxygen species (ROS) have been implicated in the pathogenesis of various prominent human diseases, including cancer, ${ }^{1}$ chronic inflammation, ${ }^{2}$ neurodegenerative disorders, ${ }^{3}$ and even ophthalmologic conditions. ${ }^{4}$ The clinical effects arise from uncontrolled generation of metabolic ROS overwhelming the cellular antioxidant defenses. Overproduction of ROS, including singlet oxygen $\left(\mathrm{O}_{2}{ }^{1} \Delta_{\mathrm{g}}\right)$ species, hydroxyl $\left({ }^{\bullet} \mathrm{OH}\right)$ radicals, and superoxide $\left(\mathrm{O}_{2}{ }^{\bullet-}\right)$ anions, causes destruction of biomolecules such as lipids, proteins, and DNA, which often leads to irreversible tissue damage. ${ }^{5,6}$ Over the last decade, the development of nano cerium-oxide (nanoceria)-based ROS neutralizing therapeutics has received increasing attention because of the particle's intrinsic $\mathrm{Ce}^{3+} / \mathrm{Ce}^{4+}$ switchable oxidation states. The redox cycling facilitates reversible stoichiometric storing $\left(\mathrm{CeO}_{2}\right)$ and release of oxygen $\left(\mathrm{CeO}_{2-\delta}\right)$, rendering nanoceria as a potential self-regenerating ROS scavenger in response to the presence of both oxidizing and reducing oxygen species in cells. ${ }^{4,7-9}$ Research has focused on enhancing the oxygen storage and release capacity of nanoceria for biological ROS modulation, which is widely thought to be a function of the formation and mobility of oxygen vacancies. ${ }^{10-12}$ Structural distortions through elemental doping of nanoceria have been shown to introduce defects for enhanced oxygen storage and release capacity via $\mathrm{Ce}^{3+} /$ $\mathrm{Ce}^{4+}$ transition of the particles for antioxidant activity. ${ }^{13-16}$ However, a solid-state engineering approach for an intended biological application has the potential to give rise to unexpected biological fates and functions of nanoparticles.

Underlining the significance of cellular physiological responses to nanoparticles, herein, we report the biological antioxidant effects of structurally distorted, oxygen vacancyengineered nanoceria. ROS-producing inflammatory cells, in this case, activated U937 monocyte/macrophages (monocytes are associated with many inflammatory progressions, including in rheumatoid arthritis), were found to internalize particles most efficiently when the particles are with high levels of surface oxygen vacancies, and these particles subsequently scavenged intracellular ROS. The present work highlights the importance of surface defects to render the nanoparticle

Received: February 24, 2019

Accepted: May 17, 2019

Published: May 30, 2019 


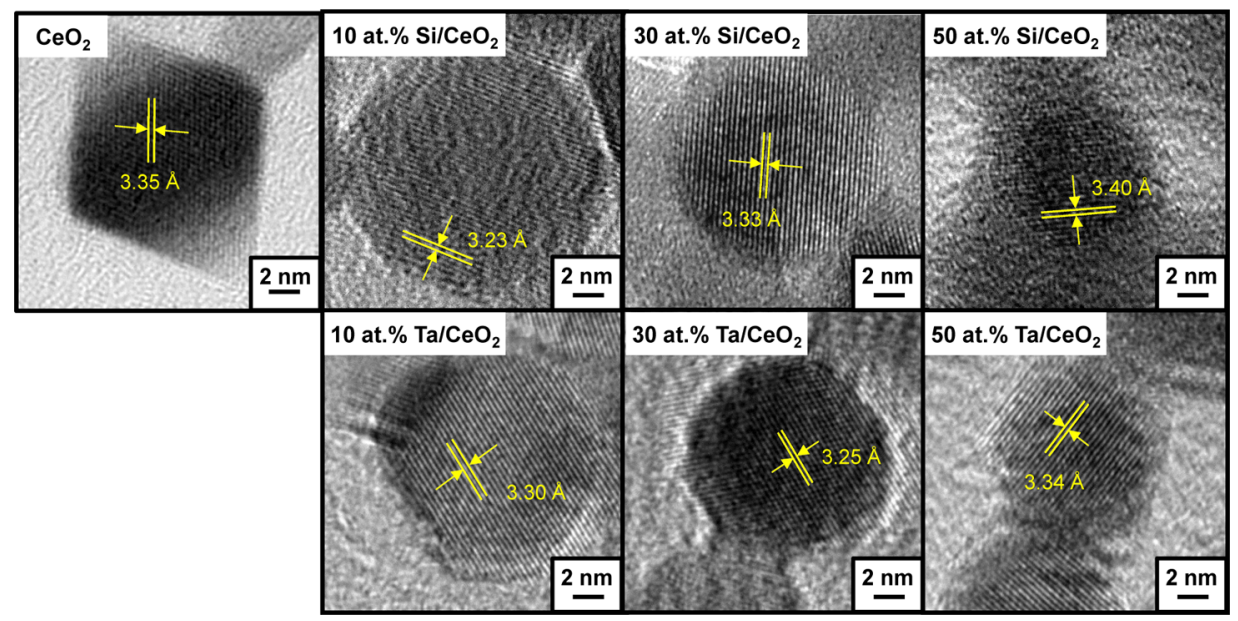

Figure 1. HR-TEM of FSP-synthesized nanoceria with 10, 30, and 50 at. \% Si and Ta dopings. Yellow lines indicate measurements of lattice spacing.

bioavailable for cellular uptake and therefore enabling the intended activity, in this case, as ROS scavenger, to take place intracellularly. The study is expected to shift the current target of engineering of the antioxidant nanoparticle from enhancement of the oxygen exchange capacity to also include design of distinctive surface characteristics.

\section{RESULTS AND DISCUSSION}

To introduce structural defects, nanoceria was doped with increasing concentrations of $\mathrm{Si}^{4+}$ and $\mathrm{Ta}^{5+}$ at 10,30 , and 50 at. $\%$, producing $\mathrm{Si}-\mathrm{CeO}_{2}$ and $\mathrm{Ta}-\mathrm{CeO}_{2}$. The particles were synthesized via rapid flame spray pyrolysis (FSP) of cerium 2ethylhexanoate premixed with tetraethyl orthosilicate and tantalum(V) ethoxide for $\mathrm{Si}$ and $\mathrm{Ta}$ dopings, respectively. The FSP technique allows for a one-step, precise stoichiometric synthesis of the doped nanoceria. The incorporation of $\mathrm{Si}^{4+}$ and $\mathrm{Ta}^{5+}$ with smaller ionic radii of 0.26 and $0.74 \AA$, respectively, compared to that of $\mathrm{Ce}^{3+}$ of $1.15 \AA$ or $\mathrm{Ce}^{4+}$ of $0.97 \AA^{17}$ distorts the crystal structure of nanoceria (Figure 1).

The presence of dopants transforms the particle morphology from the well-defined rhombohedral structure with sharp edges of the nanoceria [X-ray diffraction (XRD)-estimated average crystal size, $d_{\mathrm{XRD}}=11.9 \mathrm{~nm}$, Figure $\mathrm{S} 1$ and Table 1] to fully spherical morphologies with Si doping $\left(d_{\mathrm{XRD}}=10.1-11.6 \mathrm{~nm}\right)$ and into "spheroid" morphologies with Ta doping $\left(d_{\mathrm{XRD}}=\right.$ $10.8-11.4 \mathrm{~nm}$, with a smaller $d_{\mathrm{XRD}}=7.9 \mathrm{~nm}$ at 50 at. $\%$ doping). Similar findings have been reported for FSPsynthesized ceria-zirconia with $\mathrm{Si}$ and $\mathrm{Al}$ dopings, resulting in changes in the particle morphology from polyhedral to spherical, even at 3 wt \% doping. ${ }^{18}$ Doping of Si at 30 and 50 at. \% resulted in the formation of an amorphous layer, visible as a gel-like layer surrounding the particles (Figure 1). Further zeta potential analysis of these particles (Figure $2 \mathrm{a}$ ) revealed a significant isoelectric point (IEP) shift from $\mathrm{pH} \approx 8$ for the nanoceria to $\mathrm{pH} \approx 4$. The IEP of silica $\left(\mathrm{SiO}_{2}\right)$ is $\sim 2$, and thus the shift indicated the transformation of the surface properties of 30 and 50 at. $\% \mathrm{Si}-\mathrm{CeO}_{2}$ toward silica, inferring the formation of a silica gel-like surface layer. ${ }^{19}$ XRD analysis, shown in Figure S1, revealed negligible changes in the diffraction spectra for all Si-doped nanoceria relative to the nanoceria, consistent with the only small contraction found from transmission electron microscopy (TEM) imaging (Figure 1). This contraction is evidence of $\mathrm{Si}$ incorporation
Table 1. BET Specific Surface Area and $\mathrm{O}_{2}$-TPD Results for FSP-Synthesized Nanoceria with 10, 30, and 50 at. \% Si and Ta Dopings

\begin{tabular}{|c|c|c|c|c|c|}
\hline & $\begin{array}{c}\text { surface } \\
\text { area } \\
\left(\mathrm{m}^{2} / \mathrm{g}\right)\end{array}$ & $\begin{array}{c}\text { crystal } \\
\text { size } \\
(\mathrm{nm})^{a}\end{array}$ & $\begin{array}{c}\text { relative } \\
\text { OSC }^{b}\end{array}$ & $\begin{array}{l}\text { low temp. } \\
\text { peak portion } \\
(\%)^{c}\end{array}$ & $\begin{array}{l}\text { low temp. } \\
\text { peak }\left({ }^{\circ} \mathrm{C}\right)\end{array}$ \\
\hline $\mathrm{CeO}_{2}$ & 146 & 11.9 & 1.00 & 58.2 & 91 \\
\hline $\begin{array}{l}10 \text { at. } \% \\
\mathrm{Si}-\mathrm{CeO}_{2}\end{array}$ & 108 & 10.9 & 0.92 & 46.1 & 127 \\
\hline $\begin{array}{l}30 \text { at. } \% \\
\mathrm{Si}-\mathrm{CeO}_{2}\end{array}$ & 101 & 10.1 & 1.00 & 5.3 & 86 \\
\hline $\begin{array}{l}50 \text { at. } \% \\
\mathrm{Si}-\mathrm{CeO}_{2}\end{array}$ & 110 & 11.6 & 1.22 & & \\
\hline $\begin{array}{l}10 \text { at. } \% \\
\mathrm{Ta}-\mathrm{CeO}_{2}\end{array}$ & 97 & 10.9 & 0.93 & 39.0 & 147 \\
\hline $\begin{array}{l}30 \text { at. } \% \\
\mathrm{Ta}-\mathrm{CeO}_{2}\end{array}$ & 78 & 11.6 & 0.92 & 6.4 & 88 \\
\hline $\begin{array}{l}50 \text { at. } \% \\
\mathrm{Ta}-\mathrm{CeO}_{2}\end{array}$ & 56 & 7.9 & 0.73 & & \\
\hline
\end{tabular}

${ }^{a}$ XRD-estimated average crystal size. ${ }^{b}$ Relative OSC calculated from the volume of oxygen desorbed relative to the nanoceria. ${ }^{c}$ Percentage of total oxygen desorbed arising from the lower temperature peak (shaded in blue in Figure 2b).

into the nanoceria lattice (due to its smaller ionic radius), as later confirmed by X-ray photoelectron spectroscopy (XPS) depth profiling. For the Ta doping, further mismatch in ionic valency ( $\mathrm{Ta}^{5+}$ compared to $\mathrm{Ce}^{3+}$ and $\mathrm{Ce}^{4+}$ ) is also thought to contribute to the structural distortion. ${ }^{20}$ At 50 at. \% Ta doping, the XRD spectrum suggests the presence of $\mathrm{TaO}_{2}$ phases (Figure S1). All samples exhibit high crystallinity with welldefined lattice fringes (Figure 1).

Studies of the oxygen vacancies of the structurally distorted nanoceria yield interesting insights into the surface and bulk defects as a result of dopant incorporation. Oxygen vacancies in nanoceria are formed to compensate for the positive charge reduction to $\mathrm{Ce}^{3+}$ and are theoretically more stable at the surface than in the bulk crystal. ${ }^{10,21,22}$ To understand the nature of oxygen vacancies in the doped nanoceria, $\mathrm{O}_{2}$ temperature-programmed desorption (TPD) studies were carried out to probe both the oxygen-storage capacity (OSC) of the materials along with the surface/bulk accessibility of the oxygen vacancies (Figure $2 b$ and Table 1). At low temperature, $<200{ }^{\circ} \mathrm{C}$, desorption peaks of the $\mathrm{O}_{2}$ TPD profile are associated with the release of surface oxygen, 

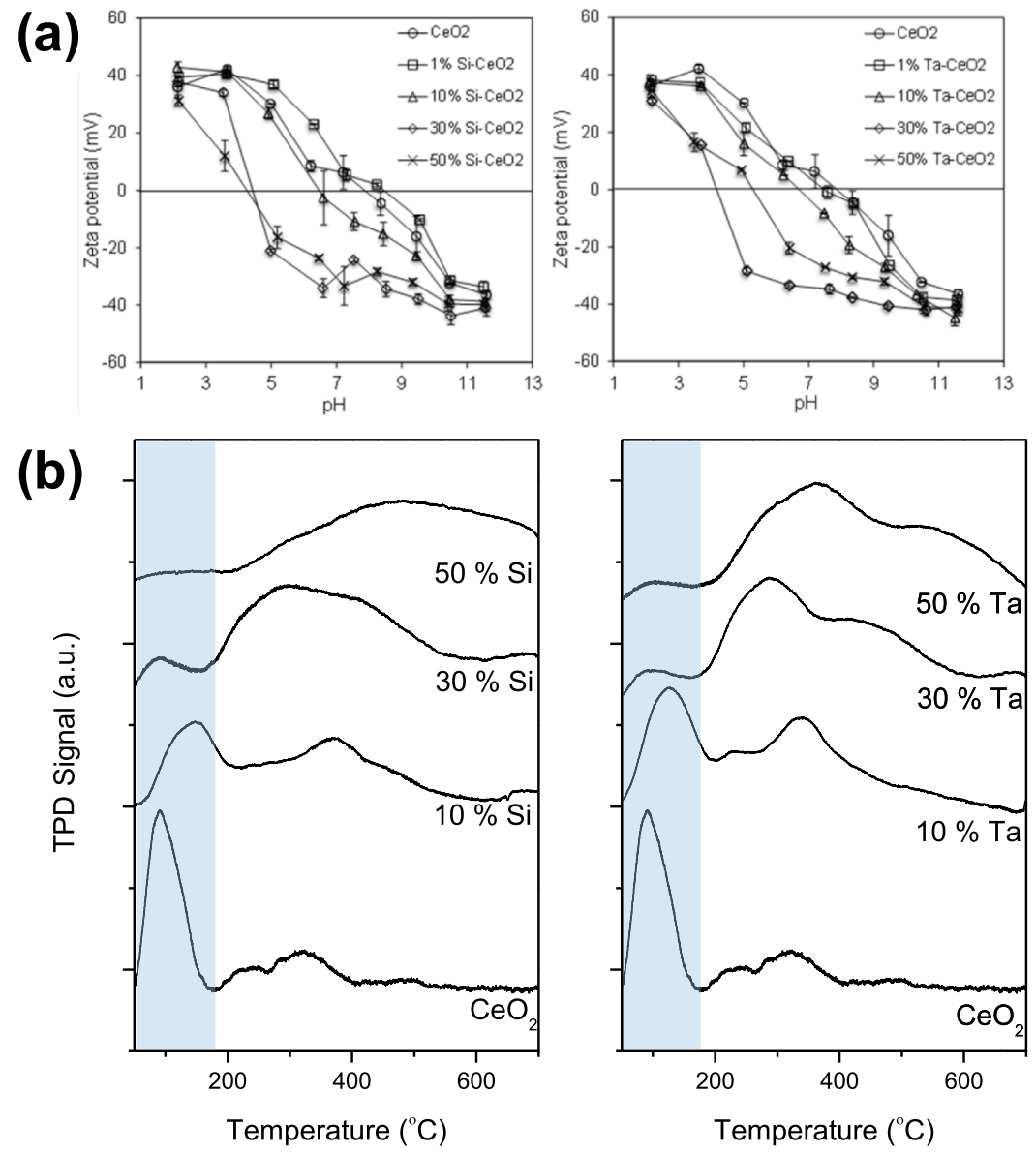

Figure 2. (a) Zeta potential and (b) $\mathrm{O}_{2}$-TPD results of FSP-synthesized nanoceria with 10, 30, and 50 at. \% Si and Ta dopings.

whereas higher temperature peaks correlate with the release of bulk oxygen, requiring more energy. ${ }^{23}$ The analysis revealed that the $\mathrm{Si}$ and $\mathrm{Ta}$ dopings affected the accessibility of the particles' oxygen vacancies, despite their generally similar total OSC relative to the nanoceria (excluding the 50 at. \% $\mathrm{Si}-$ $\mathrm{CeO}_{2}$ and $\mathrm{Ta}-\mathrm{CeO}_{2}$ with $20-30 \%$ OSC discrepancies relative to the nanoceria). The nanoceria particles contained $\sim 60 \%$ surface oxygen vacancies (of the total OSC) as indicated by the low-temperature desorption peak, enabling these particles to capture oxygen-free radicals such as intracellular ROS. A decrease in the surface oxygen vacancy was observed with 10 at. \% Si and $\mathrm{Ta}$ dopings as indicated by the reduced intensity of the low-temperature desorption peaks, representing 40$45 \%$ of their total OSC. Further increasing the $\mathrm{Si}$ and $\mathrm{Ta}$ dopant loadings to 30 and 50 at. \% caused a dramatic decrease of the surface oxygen vacancies to $\sim 5 \%$ of their total OSC. The latter was accompanied by the increased presence of the bulk oxygen vacancies, only accessible at high temperatures $(>200$ $\left.{ }^{\circ} \mathrm{C}\right)$. Note that the decrease in the surface oxygen vacancy is in agreement with the reducing \% surface $\mathrm{Ce}^{3+}$ (per unit catalyst) of the particles with increasing dopant loading (Table S1, oxygen vacancies are associated with the $\mathrm{Ce}^{3+}$ state). These findings clearly indicate a concentration-dependent effect of the dopants on the structural defects that were caused by the incorporation of elements with smaller ionic radii and/or mismatched ionic valency. In this case, $\mathrm{Si}^{4+}$ and $\mathrm{Ta}^{5+}$ altered the location of the oxygen vacancies from the surface to the bulk with increasing dopant concentrations. This migration of oxygen vacancies is also indicated by the $\mathrm{H}_{2}$-temperature- programmed reduction (TPR) profile of the nanoceria and the doped samples, as shown in Figure S2.

XPS depth profiling was carried out to further understand the nature of the surface and bulk oxygen vacancies of the Siand Ta-doped nanoceria, with Figure 3 displaying the $\mathrm{O} 1 \mathrm{~s}$ spectra and Figures S3-S5 showing the Si, Ta, and Ce profiles. The nanoceria $\mathrm{O}$ 1s spectrum (Figure 3a) revealed its surface and bulk oxygen states. At the surface, oxygen predominantly existed as lattice oxygen $\left(\sim 526 \mathrm{eV}\right.$, attributed to the $\mathrm{CeO}_{2}$ state). ${ }^{24}$ The shoulder at $\sim 528 \mathrm{eV}$ was likely a contribution of oxygen from $\mathrm{Ce}_{2} \mathrm{O}_{3}$, an indication of surface oxygen vacancy, ${ }^{21}$ that was also supported by the $\mathrm{O}_{2}$-TPD analysis. Depth profiling revealed the presence of defects in the bulk structure, as shown by the change in oxygen species in the subsurface layers, with less lattice oxygen at $\sim 526 \mathrm{eV}$ accompanied by the presence of other oxygen species possibly linked to the $\mathrm{Ce}_{2} \mathrm{O}_{3}$ form. These non- $\mathrm{CeO}_{2}$ lattice subsurface oxygen species suggest the presence of oxygen vacancies in the bulk structure. Incorporation of both $\mathrm{Si}$ and $\mathrm{Ta}$ dopants resulted in a drastic change in the $\mathrm{O}$ 1s spectra.

When examining the $\mathrm{O} 1 \mathrm{~s}$ spectra for the 10 at. \% Si-doped $\mathrm{CeO}_{2}$, distinct variations in the oxygen species compared to the nanoceria were evident. With 10 at. \% Si doping, the $\mathrm{CeO}_{2}$ lattice oxygen peak at $\sim 526 \mathrm{eV}$ became stable throughout the bulk structure (Figure $3 \mathrm{~b}$ ). This suggests that $\mathrm{Si}$ occupied the Ce sites when doped into $\mathrm{CeO}_{2}$, which helped preserve the $\mathrm{CeO}_{2}$ crystal structure, as indicated by the disappearance of oxygen peaks at $\sim 528 \mathrm{eV}$ linked to the $\mathrm{Ce}_{2} \mathrm{O}_{3}$ state and hence a decrease in bulk $\mathrm{Ce}_{2} \mathrm{O}_{3}$ defects. The $\mathrm{Si}$ occupancy of the $\mathrm{Ce}$ 

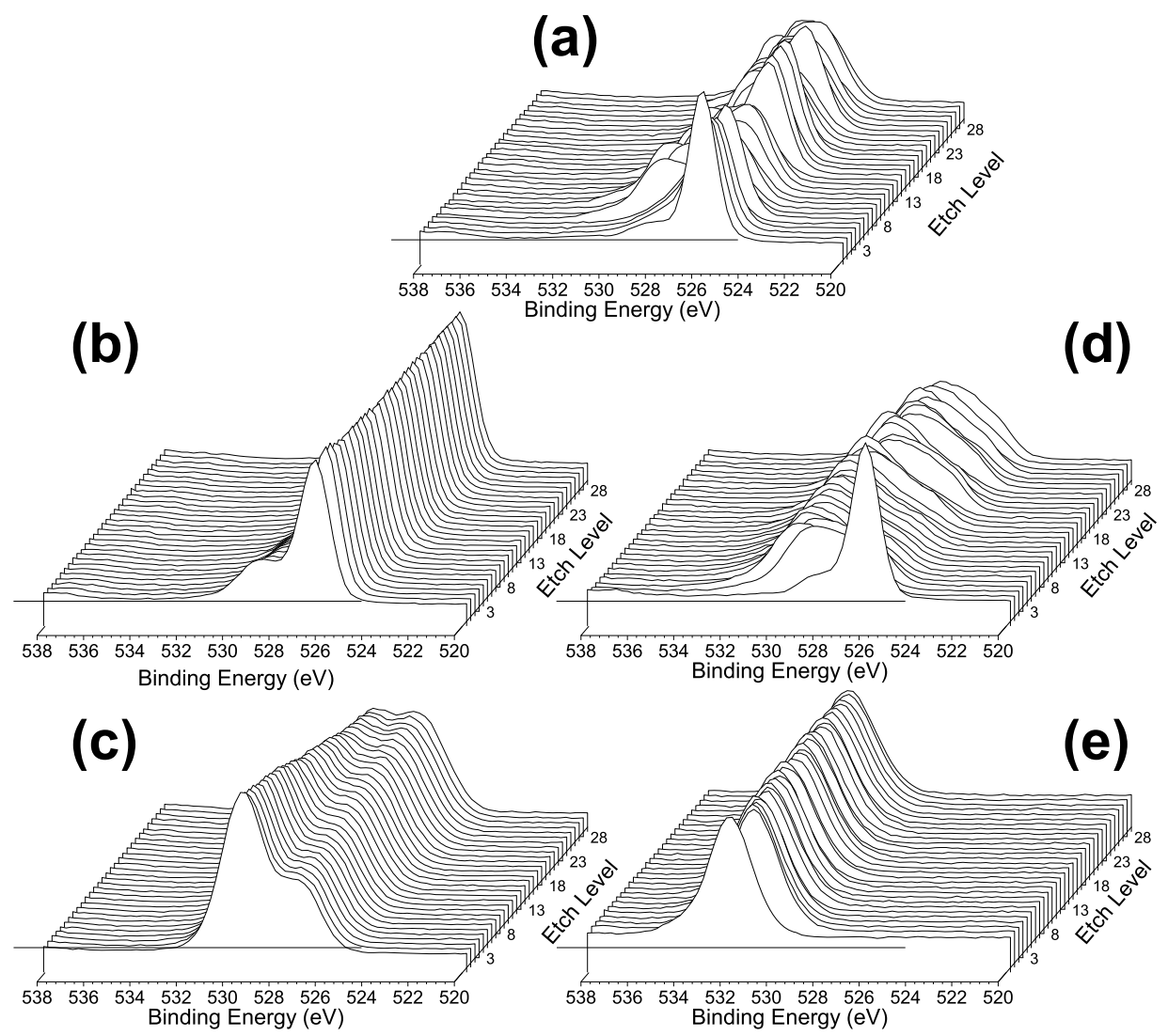

Figure 3. XPS O 1s depth profiling of FSP-synthesized (a) neat nanoceria, (b) 10 and (c) 50 at. \% $\mathrm{Si}-\mathrm{CeO}_{2}$, and (d) 10 and (e) 50 at. $\% \mathrm{Ta}-$ $\mathrm{CeO}_{2}$.

sites was also evidenced by the occurrence of the $529.5 \mathrm{eV}$ peak in the $\mathrm{Si}$ spectra, attributed to $\mathrm{SiO}_{2} \cdot{ }^{25}$ Additionally, its constant presence throughout the bulk structure indicated successful Si doping into the $\mathrm{CeO}_{2}$ crystal. The XPS data supported the particle morphologies imaged using TEM (Figure 1). The TEM images illustrate the contraction in lattice spacing in the presence of the $\mathrm{Si}$ dopant (from 3.35 to $3.23 \AA$ ), consistent with the smaller crystal lattice of $\mathrm{SiO}_{2}$ relative to $\mathrm{CeO}_{2} \cdot{ }^{17}$ When increased to 50 at. \% Si dopant level, the XPS depth profile showed a dominant presence of $\mathrm{SiO}_{2}$ $(529.5 \mathrm{eV})$ at the surface and a mix of $\mathrm{CeO}_{2}(\sim 526 \mathrm{eV})$ and $\mathrm{SiO}_{2}$ at increasing depth, with no distinguishable $\mathrm{Ce}_{2} \mathrm{O}_{3}$ peak $(\sim 528 \mathrm{eV})$ (Figure 3c). This is consistent with the presence of a $\mathrm{SiO}_{2}$ surface layer visualized under TEM (Figure 1, as also confirmed by the lower pH IEP shift shown in Figure 2a), indicating limited surface accessibility of ceria for oxygen storage and release.

Ta doping resulted in largely similar particle properties as $\mathrm{Si}$ doping. As shown in Figures 1 and 2a, Ta doping decreased the particle lattice spacing (from 3.35 to $3.25 \AA$ ) and shifted the IEP toward lower $\mathrm{pH}$. Ta dopant also reduced the oxygen vacancy sites. However, while $\mathrm{Si}$ doping preserved the $\mathrm{Ce}-\mathrm{O}$ lattice structure, the XPS depth profile of 10 at. \% Ta-doped particles revealed that most of the $\mathrm{Ce}-\mathrm{O}$ structure has disappeared (Figure 3d). The $\sim 526 \mathrm{eV}$ lattice oxygen $\mathrm{CeO}_{2}$ peak significantly diminished, with the emergence of the $\sim 532$ $\mathrm{eV}$ peak attributed to $\mathrm{TaO}_{2}$. This suggests the formation of a cerium/tantalum solid solution, as also indicated by the XRD spectra (Figure S1). As the Ta dopant level was increased to 50 at. \%, only the $\mathrm{TaO}_{2}$ peak was visible (Figure S4). The loss of oxygen adsorption sites, illustrated in the $\mathrm{O}_{2}$-TPD results
(Figure $2 \mathrm{~b}$ ), was consistent with this observation. Overall, both the $\mathrm{Si}$ - and Ta-doped ceria showed surface to bulk migration of the oxygen vacancies with increasing dopant concentration. This, as described in the following, affected the cellular responses to the particles and, in turn, their biological antioxidant activity.

Exposure of activated U937 cells to the nanoceria or the doped variants at $50 \mu \mathrm{g} \mathrm{mL}^{-1}$ for $48 \mathrm{~h}$ demonstrated that none of the particles were cytotoxic even with the increasing dopant concentration (Figure 4a). All samples exhibited comparable extent of cell proliferation as that of the medium-only system (without the particles), and this observation is consistent with our earlier studies for these cells. ${ }^{7-9}$ The biological antioxidant activities of the particles were investigated by measuring the reduction of the intracellular ROS level of the macrophages. Aligned with the high-level surface oxygen vacancies for the nanoceria, as shown in Figure $4 \mathrm{~b}$, these particles were effective $(p<0.05)$ in reducing intracellular ROS following $48 \mathrm{~h}$ exposure at $50 \mu \mathrm{g} \mathrm{mL}^{-1}$ relative to cells in medium-only. Here, we also found that the 10 at. \% Si- and Ta-doped ceria particles, both with a relatively high-level surface oxygen vacancies (although lower when compared to the nanoceria), were effective in significantly $(p<0.05)$ scavenging the intracellular ROS compared to cells in medium-only. The ROS scavenging effects, however, were absent at higher dopant concentrations of 30 and 50 at. \% for both $\mathrm{Si}$ and $\mathrm{Ta}$, as there was no difference in the level of intracellular ROS of cells exposed to these particles compared to cells exposed to medium-only. Interestingly, the low presence of oxygen vacancies for these particles was not the underlying reason for the phenomena. Analysis of particle uptake by the cell 
a
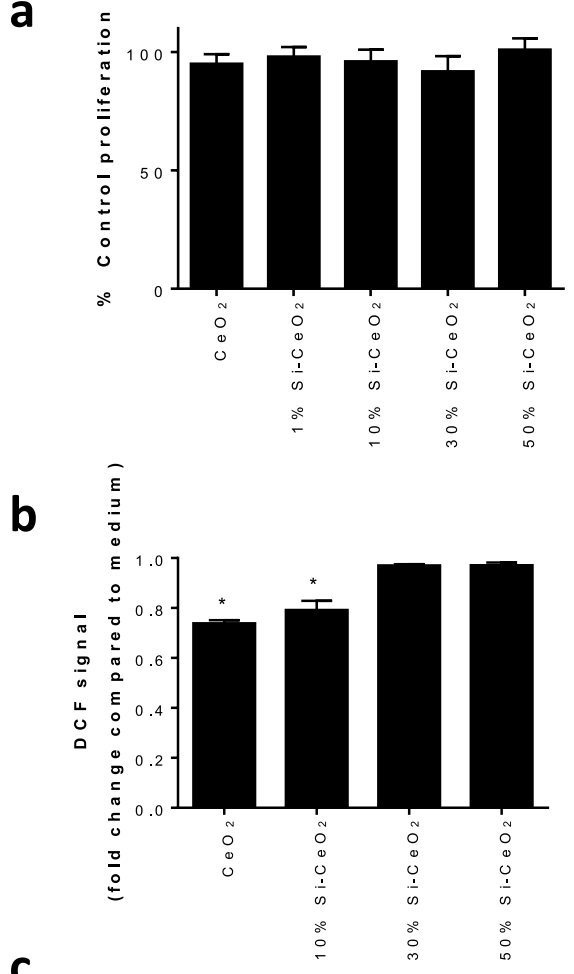

C

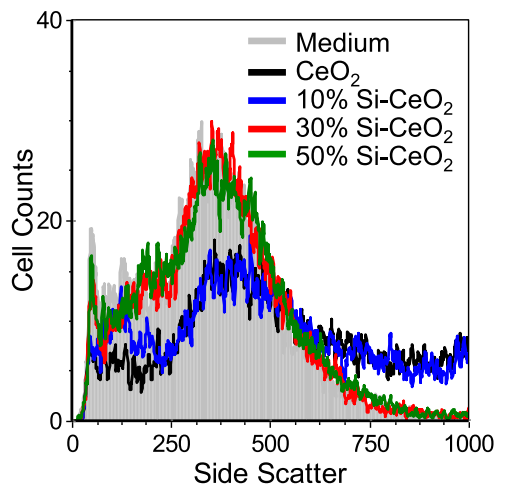

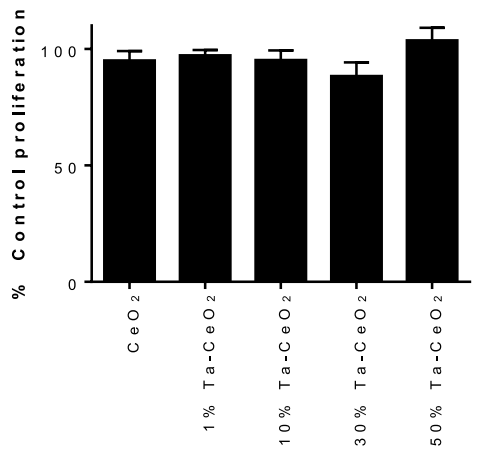
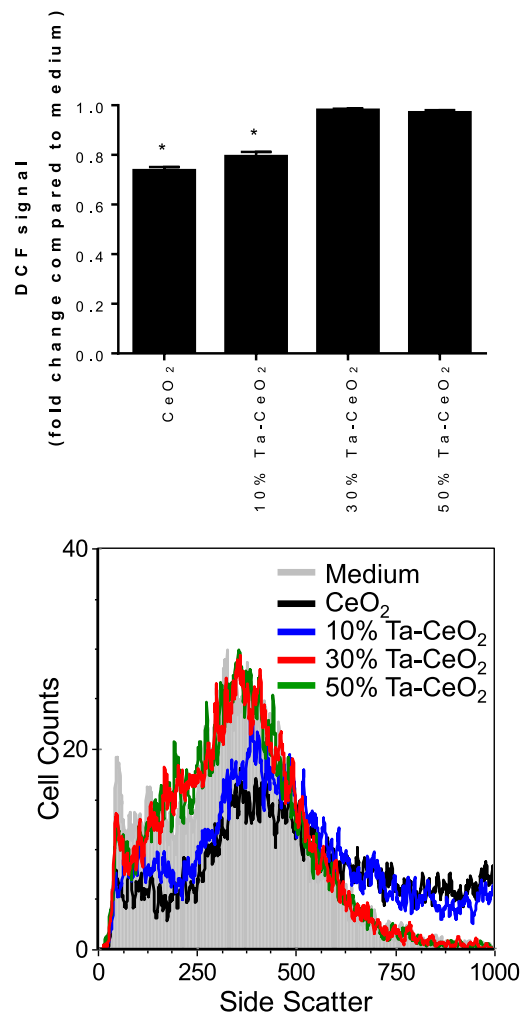

Figure 4. (a) Viability of activated U937 cells exposed to $50 \mu \mathrm{g} \mathrm{mL} \mathrm{m}^{-1}$ nanoceria or doped nanoceria compared to cells exposed to medium-only (control proliferation) analyzed after $48 \mathrm{~h}$. Data presented as mean \pm standard deviation $(\mathrm{SD}, n=3)$. Note that test conditions were found not to be statistically significant compared to cells exposed to medium-only, as analyzed by one-way analysis of variance (ANOVA) ( $p<0.05)$. (b) Intracellular ROS levels in activated U937 cells as measured by DCF fluorescence by flow cytometry after $48 \mathrm{~h}$ of exposure to $50 \mu \mathrm{g} \mathrm{mL}^{-1}$ nanoceria or doped nanoceria. Data are presented as mean fold change in DCF compared to cells exposed to medium-only \pm SD $(n=3)$ after correction for the level of DCF fluorescence in dead cells/cellular debris. $\mathrm{CeO}_{2}, 10$ at. $\% \mathrm{Si}-\mathrm{CeO}_{2}$, and 10 at. $\% \mathrm{Ta}_{\mathrm{C}} \mathrm{CeO} 2$ were found to significantly reduce intracellular ROS levels compared to cells exposed to medium-only $(p<0.05)$ as determined by one-way ANOVA. (c) Flow cytometry analysis of the nanoceria and doped nanoceria uptake into activated U937 cells analyzed by side scatter after $48 \mathrm{~h}$ of exposure to $50 \mu \mathrm{g}$ $\mathrm{mL}^{-1}$ particles.

revealed low levels of particle internalization for the nanoceria doped with 30 and 50 at. \% Si and Ta (Figure 4c). This is in contrast to the particle uptake observed with the nanoceria and the 10 at. $\% \mathrm{Si}-$ and Ta-doped particles (Figure 4c). Taken together, these data suggest that the cells selectively internalized the nanoceria and those doped with low level of either Si or Ta to subsequently modulate the intracellular ROS levels. It is thought that the low-level surface defects (and surface oxygen) for the $>10$ at. \% Si- and Ta-doped samples, likely due to the significant presence of $\mathrm{SiO}_{2}$ surface layers for the $\mathrm{Si}$-doped samples and the limited oxygen storage/release capacity on the surface for the Ta-doped samples, inform the variations in the cellular uptake of the particles and subsequently the intracellular ROS scavenging. Further, the uptake observed appears to be independent of the particle morphology as the doped nanoceria exhibited a round-shaped morphology as compared to the rhomboidal nanoceria (also note that the nanoceria and the doped variants were associated with comparable $\sim 200 \mathrm{~nm}$ aggregate size in the culture medium, Table S2).

In summary, the present work modulated the presence of oxygen vacancies in nanoparticles through creation of structural distortion. Intended for a biological antioxidant activity, the nanoparticles with redox cycling capability, nanoceria $\left(\mathrm{Ce}^{3+} / \mathrm{Ce}^{4+}\right)$, were doped with smaller ionic radii and/or mismatched ionic valency dopants, $\mathrm{Si}^{4+}$ and $\mathrm{Ta}^{5+}$. The controlled design of these particles facilitated not only the transformation in the particle morphology but also, interest- 
ingly, the migration of the oxygen vacancies from the surface of the particles to the bulk structure with increasing dopant concentrations. Ultimately, the study found that the uptake of nanoparticles by cells was dependent on the level of surface oxygen vacancies that subsequently enabled scavenging of intracellular ROS. Particles with low levels of surface oxygen vacancies were not bioavailable, with no uptake by the macrophage cells used in this study. Thus, the realization of the therapeutic potential of antioxidant nanoparticles requires engineering of the particles for enhanced surface defects. This is for the accessibility of their oxygen vacancies and in turn the ROS scavenging activity, and equally important, for the cellular uptake of the nanoparticles.

\section{EXPERIMENTAL SECTION}

Synthesis of Nanoceria, Si-Doped Nanoceria, and TaDoped Nanoceria. The particles were synthesized using FSP as described previously. ${ }^{26}$ For the nanoceria, xylene-dissolved liquid precursor, cerium 2-ethylhexanoate (Sigma-Aldrich, 99.9\%, 0.5 M Ce final concentration in the precursor), was fed to the center of the flame by a syringe pump. For the synthesis of $\mathrm{Si}$ - and $\mathrm{Ta}$-doped $\mathrm{CeO}_{2}$, tetraethyl orthosilicate (98\%) and tantalum(V) ethoxide (99.98\%) were used as dopant precursors, respectively. The liquid precursor was fed at $5 \mathrm{~mL} / \mathrm{min}$ and dispersed with $5 \mathrm{~L} / \mathrm{min}$ oxygen. During the synthesis, a constant pressure drop of 1.5 bar at the nozzle tip was maintained by adjusting the annular orifice gap $(0.15 \mathrm{~mm}$ spacing, at $6 \mathrm{~mm}$ radius from the center of nozzle). The spray flame was surrounded and ignited by premixed methane/ oxygen-supporting flame $(1.5 / 3.2 \mathrm{~L} / \mathrm{min}$ respectively). Supplied through a sintered metal plate ring $(8 \mathrm{~mm}$ wide, at $9 \mathrm{~mm}$ inner radius from the center of nozzle), an additional $5 \mathrm{~L} / \mathrm{min}$ oxygen flow was provided as a sheath for the supporting flame. The steep flame temperature gradient causes supersaturation of the metal vapor to form nuclei. As the flame temperature reduces downstream, the nuclei coalesce, sinter, and agglomerate and get collected as nanoparticles on fiberglass filters (Whatmann, GF/D) by the assistance of a vacuum pump (Alcatel SD series).

Characterization of Neat, Si-Doped, and Ta-Doped Ceria Nanoparticles. TEM. High-resolution TEM (HRTEM) images of the particles were captured with a Phillips CM200 microscope operating at $200 \mathrm{kV}$ equipped with a SIS CCD camera.

$X R D$. XRD analysis of the particles was performed using a Phillips X'Pert MPD diffractometer with a $\mathrm{Cu} \mathrm{K} \alpha$ radiation source $\left(\lambda \mathrm{K} \alpha_{1}=1.54056 \AA\right.$ and $\left.\lambda \mathrm{K} \alpha_{2}=1.54494 \AA\right)$ scanning in the $2 \theta$ range between $10^{\circ}$ and $100^{\circ}$ with a $0.02^{\circ}$ step size and a scan time of $1 \mathrm{~s}$ per step. PANalytical X'pert HighScore Plus software was used to determine the crystallite characteristics and average size with reference to cerianite.

Zeta Potential. The analysis was carried out using a Brookhaven ZetaPlus analyzer (operating with palladium electrodes) on $0.1 \mathrm{~g} \mathrm{~L}^{-1}$ particle suspension adjusted to $\mathrm{pH}$ 2-11 with $\mathrm{KOH}$ or $\mathrm{HNO}_{3}$.

$\mathrm{O}_{2}$-TPD Measurements. $\mathrm{O}_{2}$-TPD was used to examine the OSC of the particles. Samples were loaded in a quartz U-tube on a plug of quartz wool. Samples were pretreated to remove any adsorbed water by heating under $\mathrm{He}$ at $20 \mathrm{~mL} / \mathrm{min}$ (Coregas, $>99.996 \%$ ) to $150{ }^{\circ} \mathrm{C}$ (at $5{ }^{\circ} \mathrm{C} / \mathrm{min}$ ). The samples were then cooled to room temperature and saturated with $\mathrm{O}_{2}$ at $20 \mathrm{~mL} / \mathrm{min}$ for $2 \mathrm{~h}$ (Coregas, >99.95\%) with any physisorbed $\mathrm{O}_{2}$ being removed with a $2 \mathrm{~h}$ purge under He.
Profiles were then recorded as the samples were heated at 5 ${ }^{\circ} \mathrm{C} / \mathrm{min}$ to $900{ }^{\circ} \mathrm{C}$ under $\mathrm{He}$ at $20 \mathrm{~mL} / \mathrm{min}$.

$\mathrm{H}_{2}$-TPR Measurements. $\mathrm{H}_{2}$-TPR analysis of the particles was carried out by passing $10 \% \mathrm{H}_{2}$ in $\mathrm{He}$ at $25 \mathrm{~mL} / \mathrm{min}$ with $10{ }^{\circ} \mathrm{C} / \mathrm{min}$ ramp from room temperature, followed by hold at $850{ }^{\circ} \mathrm{C} . \mathrm{H}_{2}$ consumption was measured by a thermal conductivity detector. Prior to analysis, the particles were heated to $250{ }^{\circ} \mathrm{C}$ for $0.5 \mathrm{~h}$ to eliminate carbonates and/or other interfering adsorbed species.

XPS. XPS spectra were recorded on a Thermo ESCALAB250Xi spectrometer with monochromated $\mathrm{Al} \mathrm{K} \alpha$ energy $(1486.68 \mathrm{eV})$. For the depth profiling, the samples were etched across a $2.5 \times 2.5 \mathrm{~mm}$ region with a reference etching rate of $0.18 \mathrm{~nm} / \mathrm{s}$.

Brunauer-Emmett-Teller Surface Area. $\mathrm{N}_{2}$ adsorptiondesorption isotherms were recorded on a Micromeritics Tristar 3030 system to determine the Brunauer-Emmett-Teller (BET) surface area at $-196{ }^{\circ} \mathrm{C}$. The samples were pretreated at $150{ }^{\circ} \mathrm{C}$ for $3 \mathrm{~h}$ under vacuum.

Monocyte/Macrophage Interactions with Nanoceria. Culture of $U 937$ Cells. The human leukaemic monocyte lymphoma cell line, U937, was maintained in a monocytic cell suspension in RPMI-1640 culture medium containing 10\% (v/ v) fetal bovine serum, $100 \mathrm{U} \mathrm{mL}^{-1}$ penicillin, and $100 \mathrm{mg}$ $\mathrm{mL}^{-1}$ streptomycin in a humidified incubator $\left(5 \% \mathrm{CO}_{2} / 95 \%\right.$ air atmosphere at $37{ }^{\circ} \mathrm{C}$ ). Treatment of U937 cells with phorbol 12-myristate 13-acetate (PMA) mimics the activation/ differentiation of monocytes in vivo. Cells were activated for 72 $\mathrm{h}$ with the addition of $100 \mathrm{nM}$ PMA to the culture medium prior to experimentation.

Cell Proliferation Analysis. The activated U937 cells were seeded in six-well tissue culture polystyrene plates at a density of $2 \times 10^{5}$ cells/well in $3 \mathrm{~mL}$ of medium. The cells were incubated for $4 \mathrm{~h}$ prior to the addition of $50 \mu \mathrm{g} \mathrm{mL}$ nanoceria or without nanoceria. Cell viability was analyzed at $48 \mathrm{~h}$ following nanoceria addition using an automated cell viability analyzer (ViCell, Beckman Coulter) that is based on trypan blue exclusion dye analysis.

Cellular ROS and Nanoceria Uptake Analyses. The level of cellular ROS was measured using the intracellular peroxidedependent oxidation of 2-,7-dichlorodihydrofluorescein diaceteate (DCFH-DA) to form a fluorescent compound, 2-, 7dichlorofluorescein (DCF). ${ }^{7-9}$ The activated U937 cells were seeded in six-well tissue culture polystyrene plates at a density of $2 \times 10^{5}$ cells/well in $3 \mathrm{~mL}$ of medium and incubated for $4 \mathrm{~h}$ prior to the addition of $50 \mu \mathrm{g} \mathrm{mL}^{-1}$ nanoceria. The presence of intracellular ROS was determined at $48 \mathrm{~h}$ following the addition of nanoceria. Cells exposed to medium-only were analyzed to determine the basal level of intracellular ROS. Cells exposed to $4 \%(\mathrm{w} / \mathrm{v})$ ethanol were used as a control for dead cells and cellular debris for the flow cytometry analysis. The activated U937 cells were removed from culture dishes by trypsinization and resuspended in Dulbecco's phosphatebuffered saline, $\mathrm{pH} 7.4$ (DPBS). The cells were centrifuged at $1000 \mathrm{rpm}$ for $6 \mathrm{~min}$, the supernatant was removed, and the cells were resuspended in $1 \mathrm{~mL}$ of DPBS and incubated with $10 \mathrm{mM}$ DCFH-DA for $30 \mathrm{~min}$ at $37{ }^{\circ} \mathrm{C}$ prior to analysis by flow cytometry. For each sample, data was acquired for $10^{4}$ gated events using a flow cytometer (BD FACSort) by measuring the fluorescence intensity along with the number of cells. Data was analyzed using the commercial software, FCS 4 Express. Cellular uptake of nanoparticles was also assessed by measuring the side scatter of each condition. 


\section{ASSOCIATED CONTENT}

\section{(5) Supporting Information}

The Supporting Information is available free of charge on the ACS Publications website at DOI: 10.1021/acsomega.9b00521.

XRD spectra and $\mathrm{H}_{2}$-TPR profiles of $\mathrm{CeO}_{2}$ and 10, 30, and 50 at. $\% \mathrm{Si}-\mathrm{CeO}_{2}$ and $\mathrm{Ta}-\mathrm{CeO}_{2} ; \mathrm{Ce}^{3+} / \mathrm{Ce}^{4+} \mathrm{XPS}$ surface composition of $\mathrm{CeO}_{2}$ and 10 and 50 at. \% Si$\mathrm{CeO}_{2}$ and $\mathrm{Ta}-\mathrm{CeO}_{2} ; \mathrm{Si} 2 \mathrm{p}$ XPS spectra of 10 and 50 at. $\% \mathrm{Si}-\mathrm{CeO}_{2}$; Ta $4 \mathrm{f}$ XPS spectra of 10 and 50 at. \% Ta$\mathrm{CeO}_{2}$; Ce 3d XPS spectra of $\mathrm{CeO}_{2}, 10$ and 50 at. \% Si$\mathrm{CeO}_{2}$, and 10 and 50 at. $\% \mathrm{Ta}-\mathrm{CeO}_{2}$; and aggregate size of $\mathrm{CeO}_{2}$ and 10,30 , and 50 at. $\% \mathrm{Si}-\mathrm{CeO}_{2}$ and $\mathrm{Ta}-$ $\mathrm{CeO}_{2}$ in the cell culture medium measured by dynamic light scattering (PDF)

\section{AUTHOR INFORMATION}

\section{Corresponding Authors}

*E-mail: Cindy.Gunawan@uts.edu.au (C.G.).

*E-mail: m.lord@unsw.edu.au (M.S.L.).

ORCID $\odot$

Cindy Gunawan: 0000-0002-2957-1347

Megan S. Lord: 0000-0002-0506-9811

Emma Lovell: 0000-0002-9027-0316

Roong Jien Wong: 0000-0002-3260-877X

Riti Mann: 0000-0003-4772-0139

Rose Amal: 0000-0001-9561-4918

\section{Notes}

The authors declare no competing financial interest.

\section{ACKNOWLEDGMENTS}

We would like to thank Prof Wey Yang Teoh at the City University of Hong Kong for his support in the synthesis of the nanoparticles and the early stage analyses. This work is financially supported by the Australian Research Council Discovery Project (DP1097149).

\section{REFERENCES}

(1) Yang, H.; Villani, R. M.; Wang, H.; Simpson, M. J.; Roberts, M. S.; Tang, M.; Liang, $\mathrm{X}$. The role of cellular reactive oxygen species in cancer chemotherapy. J. Exp. Clin. Cancer Res. 2018, 37, 266.

(2) Forrester, S. J.; Kikuchi, D. S.; Hernandes, M. S.; Xu, Q.; Griendling, K. K. Reactive oxygen species in metabolic and inflammatory signalling. Circ. Res. 2018, 122, 877-902.

(3) Kim, G. H.; Kim, J. E.; Rhie, S. J.; Yoon, S. The role of oxidative stress in neurodegenerative diseases. Exp. Neurobiol. 2015, 24, 325340.

(4) McMonnies, C. Reactive oxygen species, oxidative stress, glaucoma and hyperbaric oxygen therapy. J. Optom. 2018, 11, 3-9.

(5) Hirst, S. M.; Karakoti, A. S.; Tyler, R. D.; Sriranganathan, N.; Seal, S.; Reilly, C. M. Anti-inflammatory properties of cerium oxide nanoparticles. Small 2009, 5, 2848-2856.

(6) Celardo, I.; Pedersen, J. Z.; Traversa, E.; Ghibelli, L. Pharmacological potential of cerium oxide nanoparticles. Nanoscale 2011, 3, 1411-1420.

(7) Lord, M. S.; Jung, M.; Teoh, W. Y.; Gunawan, C.; Vassie, J. A.; Amal, R.; Whitelock, J. M. Cellular uptake and reactive oxygen species modulation of cerium oxide nanoparticles in human monocyte cell line U937. Biomaterials 2012, 33, 7915-7924.

(8) Lord, M. S.; Tsoi, B.; Gunawan, C.; Teoh, W. Y.; Amal, R.; Whitelock, J. M. Anti-angiogenic activity of heparin functionalised cerium oxide nanoparticles. Biomaterials 2013, 34, 8808-8818.
(9) Ting, S. R. S.; Whitelock, J. M.; Tomic, R.; Gunawan, C.; Teoh, W. Y.; Amal, R.; Lord, M. S. Cellular uptake and activity of heparin functionalised cerium oxide nanoparticles in monocytes. Biomaterials 2013, 34, 4377-4386.

(10) Esch, F.; Fabris, S.; Zhou, L.; Montini, T.; Africh, C.; Fornasiero, P.; Comelli, G.; Rosei, R. Electron Localization Determines Defect Formation on Ceria Substrates. Science 2005, 309, 752-755.

(11) Mamontov, E.; Egami, T.; Brezny, R.; Koranne, M.; Tyagi, S. Lattice defects and oxygen storage capacity of nanocrystalline ceria and ceria-zirconia. J. Phys. Chem. B 2000, 104, 11110-11116.

(12) Deshpande, S.; Patil, S.; Kuchibhatla, S. V.; Seal, S. Size dependency variation in lattice parameter and valency states in nanocrystalline cerium oxide. Appl. Phys. Lett. 2005, 87, 133113.

(13) Tsai, Y.-Y.; Oca-Cossio, J.; Lin, S.-M.; Woan, K.; Yu, P.-C.; Sigmund, W. Reactive oxygen species scavenging properties of $\mathrm{ZrO}_{2^{-}}$ $\mathrm{CeO}_{2}$ solid solution nanoparticles. Nanomedicine 2008, 3, 637-645.

(14) Saraf, N.; Barkam, S.; Peppler, M.; Metke, A.; VázquezGuardado, A.; Singh, S.; Emile, C.; Bico, A.; Rodas, C.; Seal, S. Microsensor for limonin detection: An indicator of citrus greening disease. Sens. Actuators, B 2019, 283, 724-730.

(15) Singh, S.; Kumar, A.; Karakoti, A.; Seal, S.; Self, W. T. Unveiling the mechanism of uptake and sub-cellular distribution of cerium oxide nanoparticles. Mol. BioSyst. 2010, 6, 1813-1820.

(16) Gupta, A.; Das, S.; Neal, C. J.; Seal, S. Controlling the surface chemistry of cerium oxide nanoparticles for biological applications. J. Mater. Chem. B 2016, 4, 3195-3202.

(17) Shannon, R. D. Revised effective ionic radii and systematic studies of interatomic distances in halides and chalcogenides. Acta Crystallogr., Sect. A: Cryst. Phys., Diffr., Theor. Gen. Crystallogr. 1976, 32A, 751-767.

(18) Schulz, H.; Stark, W. J.; Maciejewski, M.; Pratsinis, S. E.; Baiker, A. Flame-made nanocrystalline ceria/zirconia doped with alumina or silica: Structural properties and enhanced oxygen exchange capacity. J. Mater. Chem. 2003, 13, 2979-2984.

(19) Li, D.; Teoh, W. Y.; Selomulya, C.; Woodward, R. C.; Amal, R.; Rosche, B. Flame-sprayed superparamagnetic bare and silica-coated maghemite nanoparticles: Synthesis, characterization, and protein adsorption-desorption. Chem. Mater. 2006, 18, 6403-6413.

(20) Le Gal, A.; Abanades, S. Dopant incorporation in ceria for enhanced water-splitting activity during solar thermochemical hydrogen generation. J. Phys. Chem. C 2012, 116, 13516-13523.

(21) Ying, J. Y.; Tschöpe, A. Synthesis and characteristics of nonstoichiometric nanocrystalline cerium oxide-based catalysts. Chem. Eng. J. Biochem. Eng. J. 1996, 64, 225-237.

(22) Sayle, T. X. T.; Parker, S. C.; Catlow, C. R. A. The role of oxygen vacancies on ceria surfaces in the oxidation of carbon monoxide. Surf. Sci. 1994, 316, 329-336.

(23) Ma, L.; Wang, D.; Li, J.; Bai, B.; Fu, L.; Li, Y. Ag/ $\mathrm{CeO}_{2}$ nanospheres: Efficient catalysts for formaldehyde oxidation. Appl. Catal., B 2014, 148-149, 36-43.

(24) Flege, J. I.; Kaemena, B.; Höcker, J.; Bertram, F.; Wollschläger, J.; Schmidt, T.; Falta, J. Ultrathin, epitaxial cerium dioxide on silicon. Appl. Phys. Lett. 2014, 104, 131604.

(25) Larina, T. V.; Dovlitova, L. S.; Kaichev, V. V.; Malakhov, V. V.; Glazneva, T. S.; Paukshtis, E. A.; Bal'zhinimaev, B. S. Influence of the surface layer of hydrated silicon on the stabilization of $\mathrm{Co}^{2+}$ cations in $\mathrm{Zr}$-Si fiberglass materials according to XPS, UV-Vis DRS, and differential dissolution phase analysis. RSC Adv. 2015, 5, 7989879905

(26) Mädler, L.; Kammler, H. K.; Mueller, R.; Pratsinis, S. E. Controlled synthesis of nanostructured particles by flame spray pyrolysis. J. Aerosol Sci. 2002, 33, 369-389. 